\title{
Effects of Cigarette Smoking and Nicotine Nasal Spray on Psychiatric Symptoms and Cognition In Schizophrenia
}

Robert C. Smith, M.D., Ph.D., Abhay Singh, M.D., Mauricio Infante, M.D., Amaresh Khandat, M.D., and Angelica Kloos, B.A.

Schizophrenic patients have among the highest rates of smoking of any group of patients. Previous studies have identified psychophysiological and potential nicotinic receptor abnormalities which may be associated with this phenomenon. The effects of acute smoking or acute administration of nicotine nasal spray, after smoking abstinence, on negative symptoms and neurocognitive function have been less extensively studied in experimental designs. This study investigated the effects of smoking of high nicotine or denicotinized cigarettes, and receiving active or placebo nicotine nasal sprays, on positive and negative symptoms and cognitive functions in schizophrenic patients. The study utilized a placebo controlled crossover experimental design with pre- and post-drug evaluations on each experimental day. Smoking high nicotine cigarettes decreased negative symptoms more than denicotinized cigarettes, but smoking neither cigarette changed scores of positive symptoms, anxiety, or depression. Active nicotine nasal spray did not differentially decrease negative symptoms compared with placebo, but did improve performance on a spatial organization task, and tended to improve some measures of verbal memory and two-choice reaction time in schizophrenic patients. Both high and denicotinized cigarettes improved performance on the spatial processing task, but there was no statistically significant differential drug (Cigarette type) effect. These results suggest that acute smoking of cigarettes may transiently decrease negative symptoms in patients with schizophrenia, but it is unclear whether this effect is attributable to nicotine, other components of cigarettes, or the act of smoking. Nicotine nasal spray may modestly improve some selected aspects of cognitive function in schizophrenia.

[Neuropsychopharmacology 27:479-497, 2002]

(C) 2002 American College of Neuropsychopharmacology. Published by Elsevier Science Inc.
From the Department of Psychiatry, New York University Medical School, New York, NY (RCS, AK), Manhattan Psychiatric Center, New York, NY (RCS, AS, MI, A. Khandat, A. Kloos), and New York University, New York, NY (A. Kloos).

Dr. Infante is now with the Mayo Clinic, Department of Psychiatry, Rochester, Minn.; Dr. Singh is now with the Department of Psychiatry, University of Vermont; Dr. Khandat is now with the Department of Psychiatry, Indiana University School of Medicine. Ms. Kloos is now with the College of Osteopathic Medicine, Philadelphia, Pennsylvania.

Address correspondence to: Robert C. Smith, M.D., Ph.D., Department of Psychiatry, NYU Medical School, P.O. Box 316, Hewlett, NY 11557-0316. Tel.: (212) 369-0500, ext. 2784; (516) 5691810; Fax: (516) 569-1755; E-mail: robert.smith@med.nyu.edu

Received August 6, 2001; revised February 4, 2002; accepted February 26, 2002.

Online publication: 3/4/02 at www.acnp.org/citations/ Npp030402259.
KEY WORDS: Nicotine; Smoking; Schizophrenia; Negative symptoms; Cognitive function

Schizophrenics have a higher rate of cigarette smoking than patients with other psychiatric diagnoses or patients without definite psychiatric diagnoses (Dalack et al. 1998; Glassman 1993). In some studies, rates of smoking among schizophrenic patients have ranged from $80 \%$ to $90 \%$ (reviewed in Dalack et al. 1998). It has been hypothesized that nicotine may compensate for physiological deficits in schizophrenia, and this may be involved as an explanation for the high rate of smoking in schizophrenia (Glassman 1993). Recent studies have presented evidence that nicotine transiently corrects or 
ameliorates some of the psychophysiological abnormalities found in schizophrenic patients. Specifically, in schizophrenics, smoking a cigarette corrected the diminished gating response of the P50 auditory evoked potential, in an auditory tone paradigm which measured P50 negative response to a test tone vs. a conditioned tone. Cigarette smoking also reduced abnormalities in smooth pursuit eye movements reported to occur in schizophrenia (Adler et al. 1992, 1993; Olincy et al. 1998). However, to our knowledge, there are no published studies using placebo-controlled experimental designs that have shown a consistent effect of smoking on psychiatric symptoms and only one published study suggests effects of reversing neuroleptic induced impairments in cognition in schizophrenic patients (Levin et al. 1996).

One of the physiological effects of acute nicotine treatment studied in rodent brain is an increase in burst firing of dopaminergic neurons in the ventral tegmental area and increased dopamine release in the nucleus accumbens which may impact on dopaminergic function in the frontal mesolimbic dopaminergic system (Greenhoff et al. 1986). It is possible that these changes may result in greater dopamine stimulation in some of the frontal mesocortical dopaminergic projections. It has been hypothesized that some of the negative symptoms, anhedonia, and cognitive deficits that are characteristic of schizophrenia may be associated with a deficient reward reinforcement system and potential hypodopaminergic functioning in the mesocortical dopamine system. Glassman (1993), as well as other researchers, have suggested that schizophrenics may smoke at such a high rate because the dopamine release in the mesolimbic and mesocortical system produced by nicotine may transiently compensate for this hypodopaminergic state; therefore, smoking may be a form of self-medication for schizophrenics. Dopaminergic release in the ventral tegmental system may be associated with a subtype of nicotinic receptors rich in the $\alpha 3$ and possibly $\alpha 4$ components of the nicotinic receptor (Dalack et al. 1998; McGehee and Role 1995). In contrast, the deficits in sensory gating mentioned above, which nicotine transiently ameliorates, have been identified with the $\alpha 7$ subunit of the nicotinic receptor (Freedman et al. 1997) which are found in higher density in the hippocampus (McGehee and Role 1995; Sugaya et al. 1990). Pharmacological studies have shown that tolerance develops rapidly to many of the behavioral effects of nicotine in animals and this tolerance may be related to desensitization of the nicotinic receptor (Domino 1998). These results suggest that studies of acute administration of cigarettes and other forms of nicotine administration may be important to uncover the effects of these compounds in patients.

Cross-sectional studies of comparative symptoms in schizophrenic smokers and nonsmokers have produced results which are conflicting or difficult to interpret. Goff et al. (1992) reported that schizophrenics who are smokers had higher total Brief Psychiatric Rating Scale (BPRS) scores and higher positive and negative subscores of symptoms on this scale than nonsmoking schizophrenics. Further, Zeidonis et al. (1994) reported that schizophrenics who smoked had higher positive symptoms than nonsmokers, and schizophrenics who smoked heavily had the lowest number of negative symptoms. On the other hand, Hall et al. (1995) reported that the schizophrenics who had formerly smoked but were not smoking substantially at the time of assessment had lower levels of negative symptoms on a BPRS subscale than schizophrenics who were smokers. Hamera et al. (1995) and Dalack and MeadorWoodruff (1996) reported that abstinence from nicotine or decreased nicotine use may be associated with an exacerbation of schizophrenic symptoms. However, in none of these studies is the temporal relationship between smoking and changes in schizophrenic symptoms clearly defined. One recent study by Dalack et al. (1999) tried to address this time dependence problem, utilizing a paradigm in which schizophrenic patients were withdrawn from cigarette smoking and given substitute administration of active vs. placebo nicotine patch. This research group reported minimal effects of their experimental procedures on psychiatric symptoms; there was a transient decrease in SANS scores which they hypothesized might be explained by environmental effects. One interpretation of the cross sectional results could be that smoking is a marker for more severe symptomatic forms of schizophrenia, and smoking a cigarette may reduce some of these symptoms for a brief period of time. Another interpretation is that nicotine or smoking itself increases certain schizophrenic symptoms. In order to clarify these interpretations, studies of the effects of acute or chronically administered cigarettes or nicotine within defined time frames are needed.

The current study investigated the effects of acute smoking of high nicotine and denicotinized cigarettes on positive and negative symptoms in chronic schizophrenic patients, using an experimental design with double-blind control. On the basis of some of the theoretical speculations noted above, we hypothesized that smoking cigarettes with high nicotine content would decrease negative symptoms and increase positive symptoms in schizophrenic patients. On the basis of previous studies of the effects of smoking on cardiovascular measures in normal smokers (Perkins et al. 1992, 1994; Pomerleau and Pomerleau 1992), we anticipated that cigarettes high in nicotine content would produce a greater increase in pulse rate and blood pressure. On the basis of previous studies (Dalack et al. 1999; Nilsson et al. 1997; Wirshing et al. 1989) which showed that smoking or nicotine can increase dyskinesia scores, we 
Table 1. Characteristics of Patients Participating in Study

\begin{tabular}{|c|c|}
\hline Characteristic & $\begin{array}{c}\text { Mean } \pm \text { S.D.(M) or } \\
\text { Number of subjects (n) }\end{array}$ \\
\hline Age & (M) $40.8 \pm 6.9$ \\
\hline $\operatorname{Sex}(M / F)$ & (n) $30 / 1$ \\
\hline Ethnicity/Race (W/B/H) & (n) $2 / 18 / 11$ \\
\hline Diagnosis (S/SA) & (n) $25 / 6$ \\
\hline Years Ill & (M) $24.2 \pm 6.5$ \\
\hline Years Current Hospitalization & (M) $10.5 \pm 7.0$ \\
\hline Fagerstrom Tolerance Scale Score & (M) $4.5 \pm 2.1$ \\
\hline \multicolumn{2}{|l|}{ Current Treatment -Type of Neuroleptic } \\
\hline (Conventional/Atypical/Both) $^{\mathrm{a}}$ & (n) $3 / 21 / 7$ \\
\hline Mean Cotinine Level (ng/ml, pre-drug administration) & (M) $301.1 \pm 112.6$ \\
\hline \multicolumn{2}{|l|}{ Baseline Psychopathology Scores } \\
\hline PANSS Total & (M) $71.0 \pm 9.9$ \\
\hline PANSS Positive & (M) $21.3 \pm 7.0$ \\
\hline PANSS Negative & (M) $17.5 \pm 5.4$ \\
\hline SANS Total & (M) $35.8 \pm 13.6$ \\
\hline SANS Modified Total (Affective Flattening + Alogia) & (M) $12.3 \pm 9.4$ \\
\hline \multicolumn{2}{|c|}{$\begin{array}{l}\text { Legend: Ethnicity } \mathrm{W}=\text { White, } \mathrm{B}=\text { Black, Hispanic surname; Diagnosis: } \mathrm{S}=\text { Schizophrenia, } \mathrm{SA}=\text { Schizoaffec- } \\
\text { tive Disorder. } \\
\text { aThe specific antipsychotic drugs the patients were on were as follows: clozapine: } 2 \text { patients, olanzapine: } 14 \\
\text { patients, risperidone: } 5 \text { patients; fluphenazine: } 1 \text { patient; haloperidol decanoate: } 1 \text { patient; } 2 \text { atypical antipsy- } \\
\text { chotics: } 1 \text { patient, combination of conventional and atypical antipsychotics: } 7 \text { patients. }\end{array}$} \\
\hline
\end{tabular}

predicted that smoking cigarettes with high nicotine content or active nasal spray would increase scores on tardive dyskinesia rating scales.

\section{METHOD}

\section{Subjects}

Subjects were 31 patients with diagnoses of schizophrenia or schizoaffective disorder (DSM-IV criteria), who were current smokers, recruited from an inpatient tertiary care hospital. Characteristics of patients are shown in Table 1. All subjects signed informed consent for participation in the research. This study was approved by the Institutional Review Boards of Manhattan Psychiatric Center and New York University Medical School.

\section{Psychotropic Medication}

All patients were being treated with one or more neuroleptic drugs and some patients were also treated with additional supplementary medication in other classes of psychotropic medications. The patients' medications were stable over the time of the study. The neuroleptic drugs the patients used were: clozapine: 2 patients; olanzapine: 14 patients; risperidone: 5 patients; fluphenazine: 1 patient; haloperidol decanoate: 1 patient; two atypical antipsychotics: 1 patient; combination of conventional and atypical antipsychotics: 7 patients.

Accessory medications that patients used included the following: lithium: 1 patient; valproic acid: 14 pa- tients; benztropine mesylate: 18 patients; trihexyphenidyl: 1 patient.

\section{Psychiatric, Neurocognitive, and Other Evaluations}

Baseline evaluations, before any participation in any experimental sessions, included review of patients' smoking history with patient staff and chart notes, interview administration of Fagerstrom tolerance scale (Fagerstrom and Schneider 1989), and interview ratings of psychopathology on the Positive and Negative Symptom Scale (PANSS) (Kay et al. 1987) and the Scale for Assessment of Negative Symptoms (SANS) (Andreasen 1983). Subjects also received baseline evaluations with the Automated Neuropsychological Assessment Metrics (ANAM) neurocognitive battery (Reeves et al. 1993), moderate repeat schedule, which includes tests of reaction time and verbal and visual memory. They also were tested for verbal memory with a portion of the Randt memory test (Randt and Brown 1983) (5 items, digit-span, paired words, short story). The ANAM has nine different equivalent test series for the moderate repeat battery, and the Randt has five different equivalent test series. Subjects were also evaluated on a test of verbal fluency (letters, animals, groceries, and animals) (Lezak 1983). In the experimental drug sessions only the letter verbal fluency was utilized.

In the experimental sessions the subjects had preand post-drug interview evaluations, using a modified subset of items in the PANSS and SANS scales which could be rated directly from immediate interview re- 
sponses. (Many items of the PANSS and SANS full scales are based on data which cannot be assessed from an immediate interview and require longer term observation or collateral information from staff or others.) In a 10-20 min semi-structured interview, patients were rated for interview-assessed items from the PANSS scale (see Appendix for list of items), and the Affective Flattening and Alogia sub-scales from the SANS scale. (The SANS Modified Total score in this report is the sum of the scores on Alogia and Affective Flattening items).

Interview ratings were performed by a consensus of two raters. Occasionally, the second rater was absent and the ratings for that session were done by a single rater. The same interviewer or group of interviewers rated the patient in the pre-smoking and post-smoking session of each day. Inter-rater reliability for total and component scores on the PANSS and SANS scales, assessed by the intraclass correlation coefficient (ICC) (Shrout and Fleiss 1979), from joint ratings by four different pairs of examiners on different sets of patients, was as follows: ICCs (mean \pm s.d.) PANSS Total $=.0 .97$ \pm .02 ; PANSS Positive $=0.92 \pm .06$; PANSS Negative $=$ $.0 .96 \pm .02$; SANS Total $=0.95 \pm .03$; SANS Global $=$ $0.95 \pm .04$; SANS Affective Flattening total score $=$ $0.83 \pm .11$; SANS Alogia total score $=0.86 \pm .03$.

Because it was introduced during the course of the experiment, only a subset of subjects also had assessment of their abnormal movements using the SmithTRIMS Tardive Dyskinesia Scale (Smith et al. 1983), which assesses both Tardive Dyskinesia (TD) and Parkinsonian (PK) type movements. All subjects also had baseline evaluations with a slightly modified version of the Simpson-Angus scale (excluding head drop item)(Simpson and Angus 1970).

Subjects' blood pressure and pulse were assessed, with a Marshall 92 automatic blood pressure monitor, at two times in the morning before drug administration and three times after smoking or nasal spray. The mean of duplicate readings at each time was taken as the value for that time point.

\section{Cigarette and Nicotine Nasal Spray Doses and Procedures}

All subjects participated in two cigarette and two nasal spray sessions. In an additional experiment, 10 subjects later participated in two additional nasal spray sessions using a higher dose of nasal spray.

Research cigarettes were obtained from the Tobacco Research Institute. In one session the subjects smoked cigarettes moderately high in nicotine content $(1.9 \mathrm{mg})$; in the other session they smoked denicotinized (presumptive placebo) cigarettes with very low nicotine content $(0.1 \mathrm{mg})$. Subjects were offered two cigarettes on three different separated smoking occasions, over
2-2.5 h during the course of each experimental day. They were offered the second cigarette after they finished smoking the first cigarette, and were encouraged to smoke both cigarettes completely. Most subjects smoked two cigarettes on each smoking occasion although a few smoked only one on some occasions.

In the full experiment, each subject received three separate administrations of active or placebo Nicotrol nasal spray over the course of 2-2.5 h. Nicotine nasal spray $(10 \mathrm{mg} / \mathrm{ml})$ and placebo spray was provided by Pharmacia-UpJohn. The first 15 subjects received one spray to each nostril on each administration. Because preliminary results showed low nicotine levels, the next 15 subjects received 2 nasal sprays to each nostril on each administration.

In analyzing the results of the full initial experiment, described above, we found that subjects experienced some side effects-sneezing, coughing, or throat irritation-from the nasal spray administration, as has been reported in prior clinical trials with this medication (Schneider 1992; Sutherland et al. 1992). Some of these studies showed that tolerance developed to these uncomfortable side-effects with continued use of nicotine nasal spray. In addition, the nicotine levels obtained in the full experiment, using either the one or two spray dose administrations, produced considerably lower nicotine levels than the high nicotine cigarette. To look at whether the issues of low nicotine levels and sideeffects could be countered, we ran a third preliminary study, with 10 subjects, of high dose nasal spray (four spray administrations to each nostril-2 sprays twice within $5 \mathrm{~min}$ ). We tried to induce tolerance to the sideeffects by giving subjects active nasal habituation spray training sessions, where subjects received nasal spray every 15 min over $1 \mathrm{~h}$, on three different days, for habituation to the nasal spray side-effects. On these habituation days, side effects and blood pressure ratings were recorded, but none of the symptomatic or cognitive experimental measures were investigated. Eight of ten subjects showed decreased side-effect scores on day 3 compared with day 1 of the habituation sessions. After the habituation days, two experimental days were run with active and placebo nasal sprays, following the procedures described above. A nasal spray habituation day always occurred 1-2 days before each full experimental day, and the subjects were habituated again with administration of the placebo spray early on each experimental day.

\section{Nicotine and Cotinine Blood Levels}

A $10 \mathrm{ml}$ blood sample for plasma nicotine and cotinine was drawn in the morning before drug administration, and about 35-40 min after the second drug (cigarette or spray) administration. Separated plasma was stored at $-20^{\circ} \mathrm{C}$ until assayed in the Analytical Chemistry labo- 
ratory at the Nathan Kline Institute for Psychiatric Research, using a gas liquid chromatography assay with nitrogen detector and following the procedure described by Davis (1986). The detection limit of accurate quantification of nicotine with this assay is $1 \mathrm{ng} / \mathrm{ml}$ with intra- and inter-coefficient of variation of 4.7 and $5.9 \%$ respectively. Cotinine limit of detection is $5 \mathrm{ng} / \mathrm{ml}$ with intra- and inter-assay coefficients of variation of $3.4 \%$ and $5.2 \%$ respectively. Standard curves generated from drug free plasma are uniformly linear $(r=0.998)$ with low intercepts.

\section{Smoking Abstinence}

Subjects were abstinent for approximately $10-12 \mathrm{~h}$ (after midnight on the previous evening) before receiving cigarettes or nasal spray on the experimental day. The subject's abstinence was assessed from questioning the patient and ward staff, and checking the ward log book. If a patient was suspected or having smoked, his session for that day was canceled. In the later part of the experiment we acquired a vitalograph carbon monoxide $(\mathrm{CO})$ meter, to assess breath levels of $\mathrm{CO}$, which have been used in other studies to confirm smoking abstinence. In these patients an additional criterion for participation in the experimental session on that day was a CO level of $<10 \mathrm{ppm}$ on the vitalograph breath assessment.

Because caffeine has been reported to interact with cigarette effects (Perkins et al. 1994), subjects were abstinent from both cigarettes and caffeinated beverages in the morning for at least $4 \mathrm{~h}$ while they were under constant observation, before any of the tests were administered. They were not prevented from drinking coffee during their usual breakfast time, which is about $5 \mathrm{~h}$ prior to drug administration in the experimental session, and therefore were unlikely to be in a prolonged caffeine withdrawal state.

\section{Experimental Design}

The experimental design was a randomized doubleblind cross-over design using both research cigarettes and nasal spray. The order of the cigarette sessions (high vs. denicotinized cigarette) was randomized. The order of nasal spray sessions (active vs. placebo) was separately randomized. The patients always participated in the two randomized cigarette session first and the two randomized spray sessions after their two cigarette sessions. Sessions for a specific subject were run either once or twice a week. All raters were blind regarding the type of cigarette (high or denicotinized) or spray (active or placebo) that the patient had received.

Between 10:30 and 11:30 A.M. subjects had a semi- structured interview for evaluation of their psychopathology on the modified PANSS and SANS scales items. They also were tested on the ANAM moderate repeat cognitive test battery, and had their blood pressure and pulse monitored before and after these procedures. Subjects had an evaluation of their motor symptoms with the Smith-Trims TD scale. Because of time constraints, and the limits of our patients' cooperation with and/or attention to complex multiple cognitive test administrations in a relatively short period of time, we did not administer the Randt and verbal fluency tests in the pre-drug same day session, but only in the post-drug session on that day.

Between 12:30 and 1:00 P.M., subjects began drug administration by smoking two cigarettes or receiving nasal spray administration. Approximately $10 \mathrm{~min}$ after finishing their second cigarette they were again interviewed for 12-20 min using the same semi-structured interview and rating scales as in the morning session. Immediately after the interview their movements were reassessed with the Smith-TRIMS TD scale.

After finishing the ratings, subjects smoked another two cigarettes or received another nasal spray administration. This occurred about $45 \mathrm{~min}$ after their first drug administration. Ten minutes after finishing drug administration they were tested with the verbal fluency (letters) and Randt memory test (5 items acquisition, paired words acquisition, immediate recall, delayed recall, and short story). About $45 \mathrm{~min}$ after receiving the second drug administration, the subject received a third identical cigarette or nasal spray administration. Ten minutes after finishing drug administration he was retested on the ANAM moderate repeat battery.

\section{Statistical Analysis}

Statistical analysis used SPSS general linear model analysis of variance for repeated measures. The smoking and spray components of the experiments were analyzed separately. Order of drug administration was the between subjects factor. If epilson was significant by Greenhouse-Geiser or Huynth-Feldt statistics, an appropriately corrected test was performed in the within subjects ANOVA results. Pearson correlations were computed to assess the relationships between variables. Because in some conditions distributions of SANS Modified Total, PANSS or SANS component scores, or cognitive test scores, appeared to deviate from normality and this deviation was significant on the ShapiroWilk test, these scores were transformed using one or more transformations $(\ln ($ score +1$), \log ($ score +1$)$, square root(score +1$)$, square $(1+$ score $))$; if the transformation substantially improved the approximation to a normal distribution in the relevant scores, then the transformed score was used in the statistical calculations. Statistical significance is presented both for tradi- 


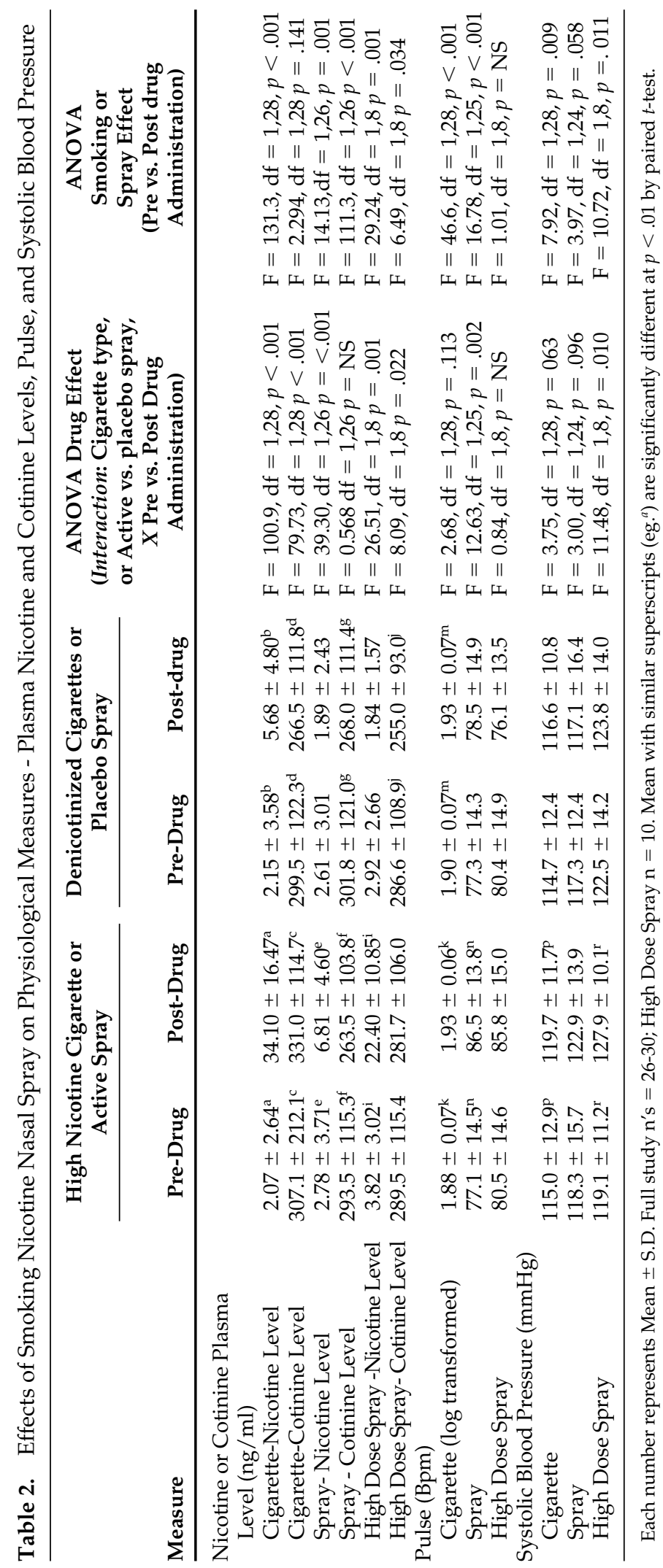


tional significance levels and Bonferroni corrected significance levels, i.e., significance levels corrected for the multiple tests (ANOVAs) conducted on several measures of the same dimension. For the measures analyzed by ANOVA, we calculated Bonferroni significance levels in the following manner. For negative symptoms we conducted analysis on five measures, and with set at $\alpha$ $=.05$ Bonferroni corrected significance levels are $p=$ .01. For other psychopathology scores we had four analyses, and with probability set at $\alpha=.05$ Bonferroni corrected significance levels are $p=.0125$. If we were more stringent in considered analyses done on all psychopathology measures, then and with probability set at $\alpha=.05$ Bonferroni corrected significance levels would be $p=.0056$. On the ANAM neurocognitive battery we conducted analysis of 15 measures, and with probability set at $\alpha=.05$ Bonferroni corrected significance levels are $p=.0033$. For verbal fluency and verbal memory we have analyzed 12 measures, and with set at $\alpha=.05$ Bonferroni corrected significance levels are $p=.0042$.

The main analyses were preformed on all the subjects with usable data. Additional analyses were performed on sub-samples filtered to exclude subjects who had anomalous nicotine values, either very high predrug administration nicotine(i.e., $>9 \mathrm{mg} / \mathrm{ml}$ ), or anomalous post-nicotine values (i.e., no increase or a decrease in nicotine blood level values).

\section{RESULTS}

\section{Subject Characteristics}

Subjects' characteristics and baseline scores are shown in Table 1. Our subjects were mostly male patients with schizophrenia who were hospitalized for long periods of time and had substantial levels of both positive and negative symptoms. Most were being treated with atypical antipsychotic medication. There was one female subject in our sample whom we included in the analyses reported below. When we excluded this female subject from the primary analyses, the results were very similar to those reported for the full sample. All our patients were current chronic smokers, who smoked at least six cigarettes each day, had smoked for years, and who often became upset when their "smoking period" on the wards were delayed or eliminated on a specific day. It was not possible to get a completely accurate self-reported smoking intensity, because our fairly psychotic patients give different estimates when they were questioned on different days. The moderate Fagerstrom tolerance scale scores may not accurately reflect our patients smoking behavior. This may be due to several factors. Many of our patients were very psychotic and cognitively impaired; verbal learning and memory deficits were prominent. It is possible they could not give accurate answers to some of the questions on this scale, and their memory problems and other cognitive deficits may have contributed to under reporting. Furthermore, the Fagerstrom tolerance scale was designated to assess smoking behavior in subjects under ad lib smoking conditions, and this model did not apply to many of our patients. Because of hospital policies many of our patients were restricted to two or three occasions of smoking in a special smoke room on the ward, although some of the patients with ground privileges could smoke additionally outside the hospital or during outside recreation.

\section{Nicotine Levels}

Nicotine levels and carbon monoxide levels recorded in the pre-drug administration assessments suggested that our subjects were generally abstinent during the preceding night and morning. All CO levels we assessed were below 2 ppm, and none approached the $10 \mathrm{ppm}$ cut off point. Most subjects had pre-drug nicotine levels range from 0 to $3 \mathrm{ng} / \mathrm{ml}$, and in only two sessions did a subject's pre-drug nicotine levels turn out to be $>9 \mathrm{mg} / \mathrm{ml}$. Correlations between carbon monoxide and pre-drug nicotine plasma levels ranged form 0.22 to 0.49 .

The chronic nature of our subjects' smoking is reflected in the high cotinine levels our subjects had in the plasma sample taken pre-drug administration, at least 10-12 $\mathrm{h}$ after smoking their last cigarette (Tables 1 and 2). However, we do not have nicotine or cotinine levels during a normal smoking day that would better reflect their levels during habitual smoking.

The high nicotine cigarette produced a substantial increase in both nicotine and cotinine levels (Table 2). However, the denicotinized cigarette also produced a significant increase in nicotine levels, but the increase only averaged $3.5 \mathrm{ng} / \mathrm{ml}$ (about $11 \%$ of the increase produced by the high nicotine cigarette). Active nicotine spray produced a small but significant increase in nicotine levels in the range of that produced by the denicotinized cigarette. The higher dose of nasal spray, used in the second half of the main study, produced higher nicotine plasma levels (mean post-spray levels $9.1 \mathrm{ng} / \mathrm{ml}$ ) than the original dose (mean post-spray levels $4.6 \mathrm{ng} / \mathrm{ml}$ ). The additional small sample experiment with the high dose spray sessions (i.e., 4 sprays to each nostril, each administration) produced considerably higher nicotine levels; mean nicotine level post-spray was $22.4 \mathrm{ng} / \mathrm{ml}$ and mean increase was $18.6 \mathrm{ng} / \mathrm{ml}$. The placebo nicotine spray did not produce an increase in nicotine levels.

\section{Negative Symptoms}

After smoking either the high or denicotinized cigarette, subjects had a significant decrease in negative 
Table 3. Effects of Smoking High Nicotine or Denicotinized Cigarettes on Negative and Positive Symptoms, and Anxiety, In Schizophrenia

\begin{tabular}{|c|c|c|c|c|c|c|}
\hline \multirow[b]{2}{*}{ Symptom Score } & \multicolumn{2}{|c|}{ High Nicotine Cigarette } & \multicolumn{2}{|c|}{ Denicotinized Cigarettes } & \multirow{2}{*}{$\begin{array}{c}\text { ANOVA } \\
\text { Drug Effect } \\
\text { (Cigarette type } X \\
\text { Pre vs. Post) } \\
(\text { df }=1,29)\end{array}$} & \multirow{2}{*}{$\begin{array}{c}\text { ANOVA } \\
\text { Smoking Effect } \\
\text { (Pre vs. Post) } \\
\text { df }=1,29 \text { ) }\end{array}$} \\
\hline & $\begin{array}{c}\text { Pre- } \\
\text { Smoking }\end{array}$ & $\begin{array}{c}\text { Post- } \\
\text { Smoking }\end{array}$ & $\begin{array}{c}\text { Pre- } \\
\text { Smoking }\end{array}$ & $\begin{array}{c}\text { Post- } \\
\text { Smoking }\end{array}$ & & \\
\hline SANS Modified Global Score ${ }^{1}$ & $2.11 \pm 0.39^{a}$ & $1.84 \pm 0.40^{\mathrm{a}}$ & $2.12 \pm 0.39$ & $2.01 \pm 0.41$ & $\mathrm{~F}=6.831, p=.014$ & $\mathrm{~F}=21.74, p<.001^{*}$ \\
\hline PANSS Modified Negative Score ${ }^{2}$ & $2.23 \pm 0.32^{\mathrm{b}}$ & $2.04 \pm 0.28^{b}$ & $2.20 \pm 0.36$ & $2.14 \pm 0.35$ & $\mathrm{~F}=5.826, p=.022$ & $\mathrm{~F}=11.675, p=.002 *$ \\
\hline SANS Modified Total Score & $16.06 \pm 8.08^{c}$ & $11.34 \pm 6.54^{\mathrm{c}}$ & $16.10 \pm 8.09$ & $13.77 \pm 7.92$ & $\mathrm{~F}=3.363, p=.077$ & $\mathrm{~F}=24.026, p<.001^{*}$ \\
\hline SANS Alogia Total ${ }^{1}$ & $2.29 \pm 0.80^{\mathrm{d}}$ & $1.79 \pm 0.71^{\mathrm{d}}$ & $2.29 \pm 0.66$ & $2.11 \pm 0.76$ & $\mathrm{~F}=3.818, p=.060$ & $\mathrm{~F}=16.743, p<.001^{*}$ \\
\hline SANS Affective Flattening & $11.72 \pm 5.73^{e}$ & $8.71 \pm 4.89^{e}$ & $11.45 \pm 6.25$ & $9.74 \pm 5.40$ & $\mathrm{~F}=1.806, p=.189$ & $\mathrm{~F}=19.647, p<.001^{*}$ \\
\hline PANSS Positive ${ }^{3}$ & $336.5 \pm 202.3$ & $393.2 \pm 212.2$ & $343.5 \pm 220.3$ & $355.7 \pm 214.2$ & $\mathrm{~F}=0.774, p=.386$ & $\mathrm{~F}=1.661, p=.208$ \\
\hline PANSS Anxiety & $1.94 \pm 1.06$ & $1.81 \pm 1.06$ & $1.93 \pm 1.09$ & $1.64 \pm 0.92$ & $\mathrm{~F}=0.854, p=.363$ & $\mathrm{~F}=1.007, p=.324$ \\
\hline
\end{tabular}

Each number represents Mean \pm S.D. $N=31$. Means with similar letter superscripts (eg ${ }^{\text {a) }}$ ) are significantly different at $p<.01$ by paired $t$-test.

Transformed scores were used in the ANOVA analysis when they substantially improved the approximation to normal distributions; ${ }^{1}$ Transform $(1+$ score $) ;{ }^{2}$ Transform LN $(1+$ score $) ;{ }^{3}$ Transform $(1+\text { score })^{2}$.

* Statistically significant by Bonferroni corrected significance levels $(\alpha=.05)$.

symptoms on all of the negative symptom measures (Table 3); these pre- vs. post-drug administration effects were significant at both traditional and Bonferroni corrected significance levels $(p<.006)$. The high dose cigarette produced a greater decrease than the denicotinized cigarette in PANSS modified negative symptom and SANS modified global scores (Table 3, Figure 1). These differential effects of high vs. denicotinized cigarettes were significant at traditional significance levels but not at Bonferroni corrected significance levels (i.e., $p \leqslant .01)$. There was a trend for the high nicotine cigarette to have greater effects in SANS modified total and SANS Alogia scores $(p<.08)$. The patients' scores after the high nicotine cigarette post-drug administration was significantly lower $(p<.01)$ than pre-drug administration evaluation on the same day for all the negative symptom measures. None of the comparisons between pre- and post-scores in the denicotinized cigarette session were statistically significant at this level.

There were no differential effects of active vs. placebo nicotine nasal spray on any measures of negative symptoms, although negative symptoms were slightly lower post-spray than pre-spray administration. The higher doses of active nasal spray, either in the full study or high dose additional sample, did not produce a greater decrease in negative symptoms than the placebo nasal spray.

\section{Other Symptoms}

There were no effects of (pre vs. post) smoking high vs. denicotinized cigarette on PANSS positive symptoms, depression or anxiety-tension. ANOVAs for the smoking effect (pre vs. post) and the drug effect (Cigarette type $\mathrm{X}$ Pre vs. post) were all non-significant $(p>10)$.
Neither active nor placebo nicotine spray produced significant changes in these measures.

\section{Blood Pressure and Pulse}

Cigarette smoking and nicotine administration have been consistently shown to increase pulse and blood pressure. In this experiment, both high nicotine and denicotinized cigarettes increased pulse, to about the same extent, but only the active nicotine nasal spray, and not placebo spray, increased pulse (see Table 2). The high nicotine cigarettes increased the second pulse reading slightly more (increase $12.5 \mathrm{bpm}$ ) than the denicotinized cigarette (increase $8 \mathrm{bpm})(\mathrm{F}=4.87, \mathrm{df}=1,28$, $p=.036)$, and there was a trend for the high nicotine cigarette to increase systolic pressure slightly more (increase $3.5 \mathrm{~mm} \mathrm{Hg}$ ) than the denicotinized cigarette (increase $1.9 \mathrm{~mm} \mathrm{Hg})(\mathrm{F}=3.75, \mathrm{df}=1,28, p=.063)$. There was also a trend $(p<.10)$ for both diastolic and systolic pressure to be increased more by the active than placebo nasal spray, with the high dose spray producing a small but significant $(p=.01)$ increase in systolic blood pressure.

\section{Cognitive Effects}

The analyses of variance showed no statistically significant differential drug effects $(p<.05)$ of smoking high vs. denicotinized cigarettes, but there were a few significant differential drug effects of active vs. placebo nasal spray.

In the cigarette sessions there were significant pre- vs. post-drug administration effects for some measures of two-choice reaction time, spatial rotation, and visual match to sample from the ANAM moderate repeat bat- 


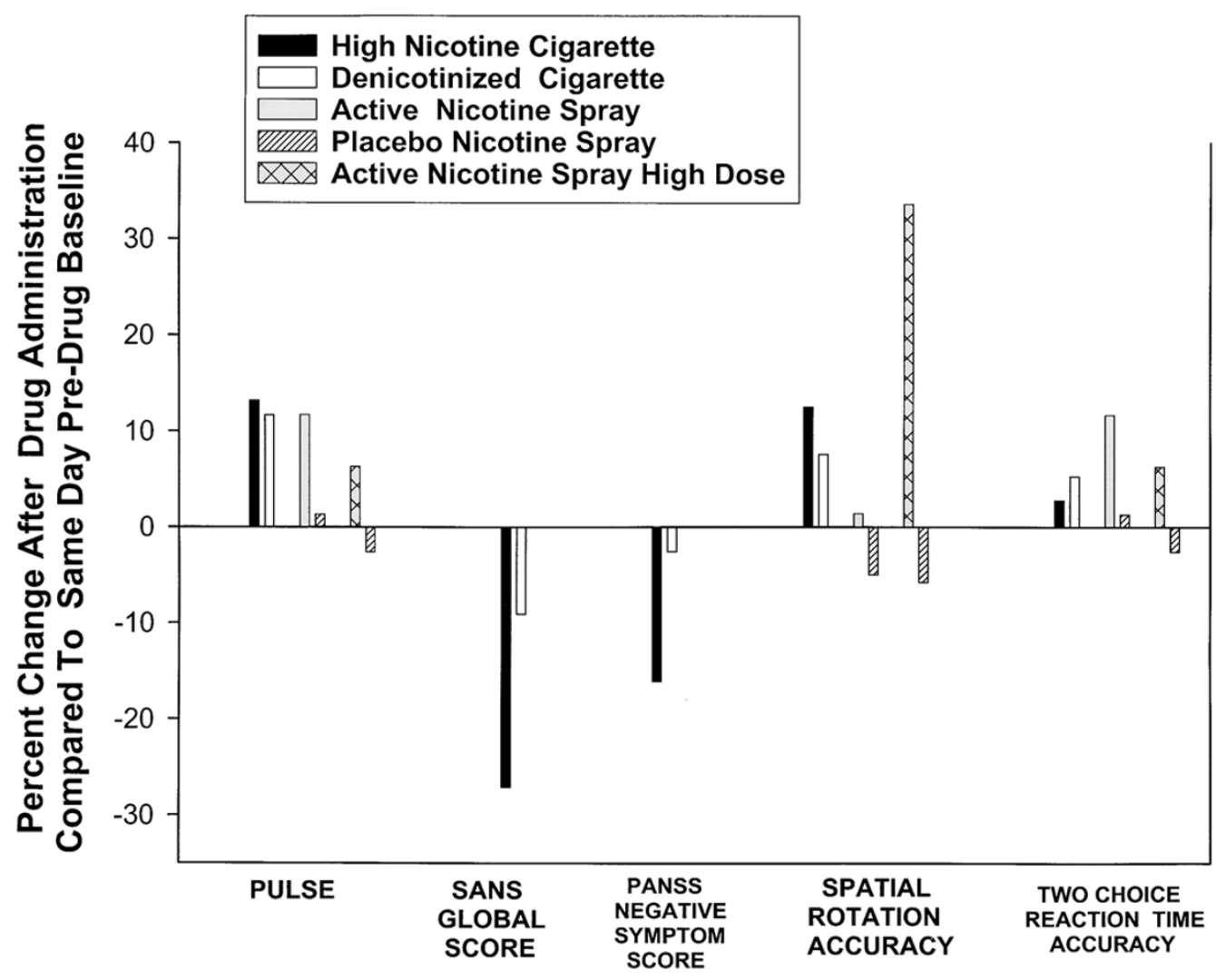

\section{AFFECTIVE, COGNITIVE, OR PHYSIOLOGICAL MEASURE}

Figure 1. Effects of cigarettes and nicotine nasal spray on pulse, symptom measures and cognition: percent change. Each bar represents mean percent change from pre-drug administration on the same experimental day (i.e. $100 \times($ (post-drug administration score - pre-drug administration score)/pre-drug administration score.

tery (Table 4, Figure 1), with both high and denicotinized cigarettes producing increased performance. There was a trend in the ANOVA $(p=.083)$ for the high nicotine cigarette to produce a greater improvement in spatial rotation efficacy (accuracy/time) than the denicotinized cigarette; scores in the high nicotine cigarette session showed a significant increase in post-smoking scores on this measure compared with pre-drug score on the same day (paired t-test, $\mathrm{t}=4.55, \mathrm{df}=30, p<.001$ ). There was also some indication of improvement over baseline scores in the high nicotine cigarette session; an analysis of covariance of baseline and post-cigarette administration scores of percent accuracy on the spatial rotation task, controlling for same session pre-drug scores as covariate, showed a significant effect of the high dose cigarette on improving spatial rotation accuracy $(\mathrm{F}=5.41, \mathrm{df}=1,28$, $p=.027)$. There were no differences in the post-session comparison of verbal memory (Randt-paired words, short story) or verbal fluency between the high nicotine and denicotinized cigarette sessions, and there were no significant improvements in performance compared with baseline scores.

In the nasal spray sessions the active spray sessions showed an increase in scores on tests of verbal memory (paired words and short story from Randt memory test), which was statistically significant ( $p=.038-.012$, Table 5) at traditional significant levels. Accuracy of the spatial rotation task (Table 4) showed a small overall improvement in the active nicotine nasal spray session and a small decrease in the placebo session with a significant drug effect $(p=.037)$. There were no significant drug effects on spatial rotation reaction time, visual match to sample, or modified Sternberg memory test. In the subjects tested in the higher dose nasal spray sub-study there were stronger drug effects on improved performance in the twochoice reaction time $(p=.008)$ and in spatial rotation accuracy $(p=.025)$, which were significant at traditional significance levels (Table 4, Figure 1). However, because of the large number of tests performed, none of these drug effects in the spray sessions, which were significant at traditional significance levels, were also statistically significant at Bonferroni corrected significance levels.

\section{Tardive Dyskinesia and Parkinsonian-Extrapyramidal Symptoms}

Neither smoking cigarettes or nasal spray administration increased scores of tardive dyskinesia (TD) or ex- 


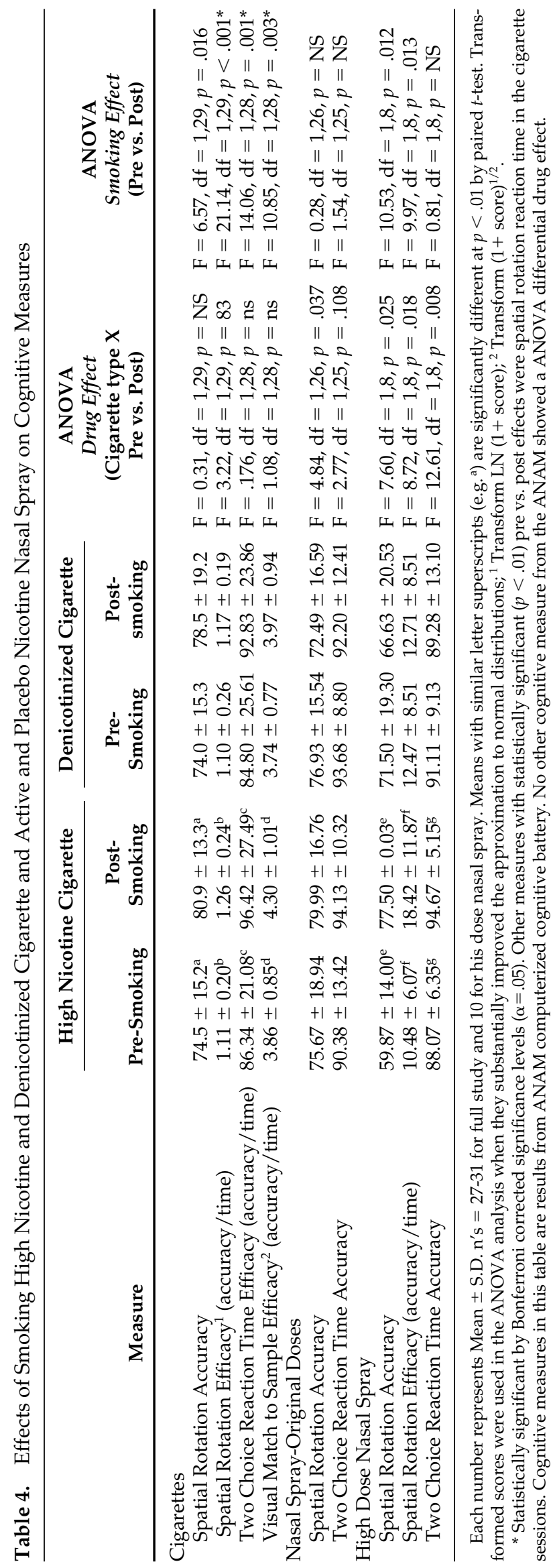

trapyramidal symptoms. There was no increase or decrease in facial or total TD scores on the Smith-Trims TD scale, and no significant changes in Parkinsonian scores on the Smith-TRIMS scale. ANOVAs showed no significant effects for either differential drug effects (interaction of Cigarette type or Active vs. placebo spray $X$ Pre vs. post) or overall drug administration effects (pre-drug vs. post-drug) for either the cigarette or nasal spray sessions. Tardive dyskinesia and parkinsonian type EPS scores were uniformly low. Total TD score averaged 1.4-1.6 (range 0-5) at pre- and post-cigarette administration, and oral-facial TD score had means of about zero at both pre- and post-cigarette administration; total parkinsonian score on the SmithTrims had mean scores of $0.8-1.5$, and mean total scores on Simpson-Angus scale at baseline evaluation was 1.2 .

Drug Effects and Nicotine Plasma Levels. There were no strong or consistent correlations between nicotine plasma levels obtained by different subjects after drug administration, or increase in nicotine plasma levels and clinical or cognitive effects. A few patients (2-3) had what appeared to be anomalous nicotine plasma levels in the smoke or spray experimental sessions. When these patients were removed, and the analyses of negative symptoms and cognitive changes were repeated, the results were very similar to the full sample. In the cigarette sessions the statistical significance of the drug effect (i.e., high vs. denicotinized cigarettes) increased slightly for the PANSS Negative symptoms $(p=.009)$ and SANS Global symptom $\operatorname{score}(p=.019)$, when the subjects with anomalous nicotine levels were removed. The significance of the differences in cognitive effects did not increase with subjects with anomalous nicotine levels were removed. There was a moderate correlation between nicotine plasma level after smoking and decrease in PANSS negative symptom score in the high dose cigarette ses$\operatorname{sion}(\mathrm{r}=.42, p<.03)$. There were no statistically significant correlations between nicotine plasma level and effects on the other symptoms, or between nicotine plasma levels and the cognitive measures which showed a significant drug effect. Although there were few correlations between subjects for nicotine plasma levels and effects, our analysis suggested that, overall, higher nicotine plasma levels in the nasal spray sessions were associated with greater cognitive effects on the spatial rotation task (Figure 2). In the original nasal spray study, the higher dose (4 puffs nasal spray) had a greater effect on this measure than the original lower dose ( 2 puffs), and the additional high dose nasal spray experiment (8 puffs), which produced the highest plasma nicotine levels, had the strongest effects on this measure. 
Table 5. Effects of Nicotine Nasal Spray on Recall of Paired Words and Short Story

\begin{tabular}{lccr}
\hline \multicolumn{1}{c}{ Task } & Nicotine Nasal Spray & Placebo Nasal Spray & ANOVA \\
\hline RANDT Paired Words Total Score & $28.23 \pm 8.25$ & $25.77 \pm 10.91$ & $\mathrm{~F}=4.36 \mathrm{df}=1,26 p=.047$ \\
RANDT Short Story Total Score & $5.87 \pm 3.40$ & $3.90 \pm 3.03$ & $\mathrm{~F}=7.58 \mathrm{df}=1,26 p=.011$ \\
\hline
\end{tabular}

$\mathrm{n}=30$.

\section{Effects of Smoking Abstinence}

It is not certain whether some of the effects of smoking and/or nicotine nasal spray reported above reflect recovery from deficits induced by withdrawal effect from abstinence of cigarette smoking for approximately $12 \mathrm{~h}$, or whether they would be seen in patients who had not been deprived of smoking cigarettes for this period of time. Our experimental design was not ideal to answer this question. However, all patients received baseline evaluations of PANSS and SANS ratings and performance on the ANAM neurocognitive battery at baseline, over one or two testing occasions, on days when they were not restricted from their normal cigarette smoking. Comparing baseline values (when the pa-

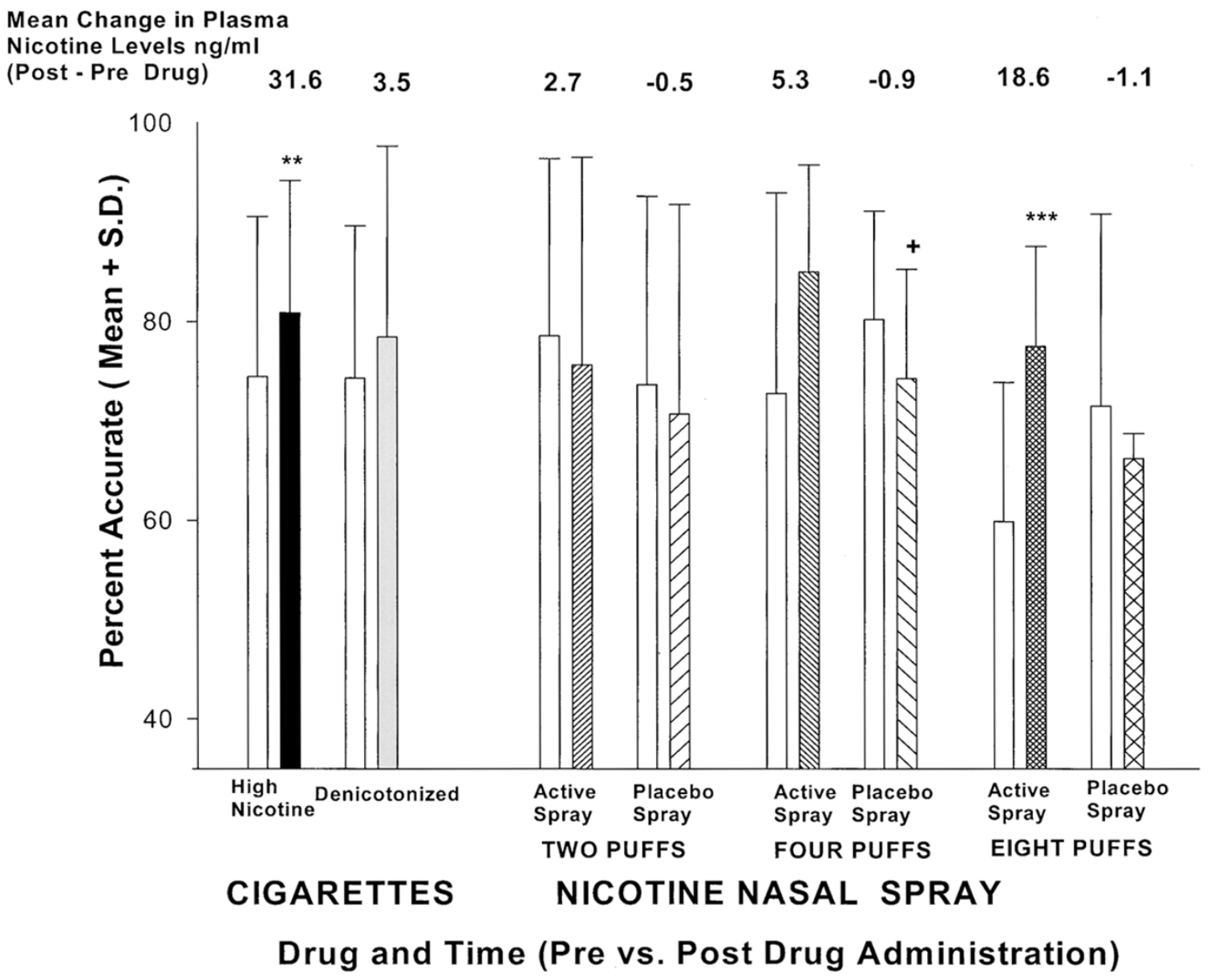

Figure 2. Effects of cigarettes and several doses of nasal spray on accuracy in spatial rotation task-relationship to nicotine plasma levels. In each comparison the pre-drug administration mean is represented by a white bar and post-drug administration is represented by a shaded or crosshsatched bar. Cigarette sessions $n=30$; 2-puff nasal spray $n=15$; 4-puff nasal spray $n=15$; 8-puff nasal spray $n=10$. Overall ANOVAs for differential drug effect (F of interaction effect - High vs. denicotinized cigarette, or Active vs. placebo spray, $\mathrm{X}$ Pre- vs. post-drug administration): cigarette: $\mathrm{F}=0.31, \mathrm{df}=1,28 p=.585$; 2-puff nasal spray $\mathrm{F}=.089, \mathrm{df}=1,13, p=.770 ; 4$-puff nasal spray $\mathrm{F}=5.409 \mathrm{df}=1,13, p=.037 ; 8$-puff nasal spray $\mathrm{F}=7.604$, $\mathrm{df}=1,8 p=.025$. Significance of difference between pre- vs. post-drug administration mean scores on given experimental day, by paired $t$-test: ${ }^{\dagger} p<.10,^{* *} p<.02,{ }^{* * *} p<.005$. 


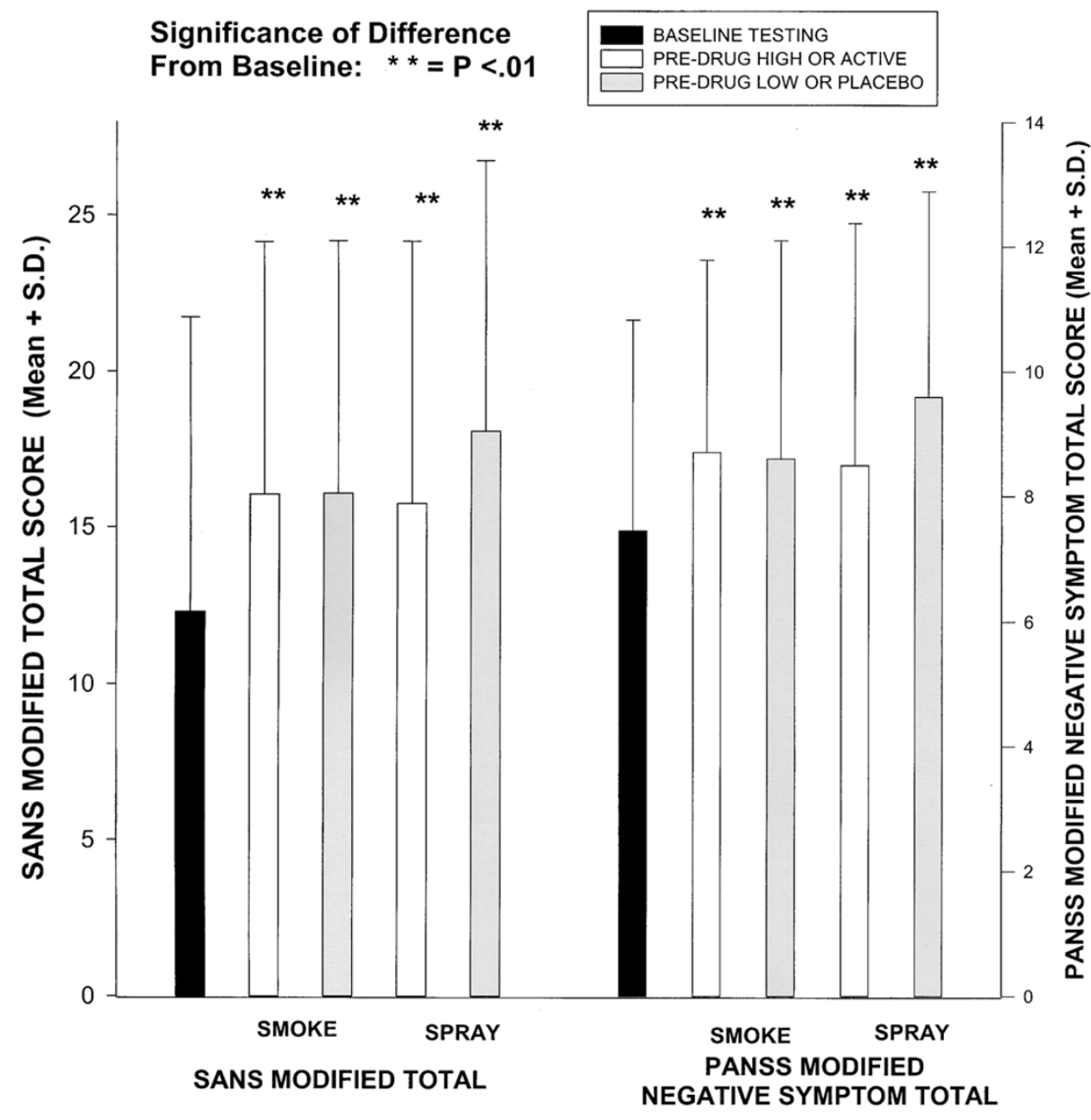

\section{TYPE OF SCORE AND TIME OF ASSESSMENT}

Figure 3. Comparison of psychopathology scores at baseline testing to pre-drug scores after 10-12 h of smoking abstinence: (A) Negative Symptom scores; (B) Positive Symptom and Anxiety scores. Each bar represents Mean + SD of score on indicated measures in baseline session or one of four experimental days in the pre-drug administration testing (2 days smoking high or denicotinized cigarettes, 2 days receiving nicotine or placebo nasal spray). Comparison of baseline with experimental sessions was analyzed separately for smoke and spray session (because of slightly different $n$ values and different order randomization) by repeated measures analysis of variance with drug order as a between-subjects factor. Significance of difference from baseline is derived from simple contrasts of time comparison generated from ANOVA. Overall ANOVA results: smoke $\mathrm{n}=31$, spray $\mathrm{n}=30$; SANS Modified Total: smoke: $\mathrm{F}=6.702, p=.002$; spray: $\mathrm{F}=8.854, p<.001$; PANSS Negative Symptom Modified Total: smoke: $\mathrm{F}=5.704, p=.005$; spray: $\mathrm{F}=6.762, p=.002$; PANSS Positive Symptom Modified Total: smoke: $\mathrm{F}=8.910, p<.001$; spray: $\mathrm{F}=3.150, p=.051$; PANSS Anxiety score: smoke: $\mathrm{F}=1.936, p=.153$; spray: $\mathrm{F}=2.697, p=.088$.

tients' normal pattern of smoking was not interfered with), to scores obtained from several occasions of predrug administration evaluations on the experimental days (when they had been deprived of smoking), may provide some indication of the effects of a 10-12 $h$ smoking abstinence on the variables we studied. Com- pared with baseline scores, negative symptoms were significantly $(p<.01)$ elevated in the morning of all experimental days during the pre-drug administration evaluations (Figure 3). This was true for all SANS and PANSS negative symptom scores except SANS Alogia. Negative symptoms scores did not significantly vary 
(B)

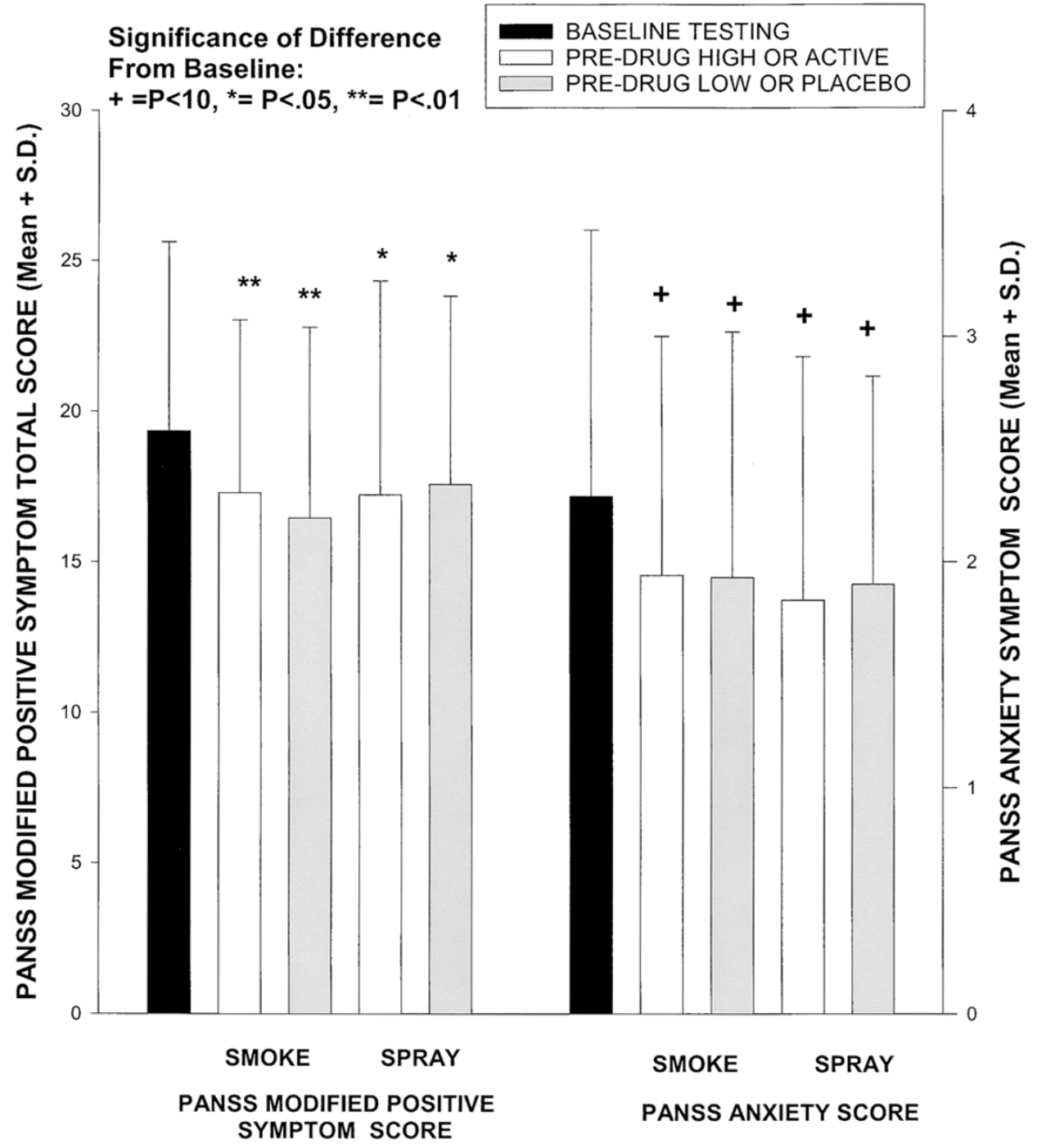

TYPE OF SCORE AND TIME OF ASSESSMENT

across the different pre-drug evaluations on the different experimental days. However, there was no increase in other symptom scores in the pre-drug symptom ratings which were obtained in subjects after 10-12 h of smoking abstinence. PANSS positive symptoms were significantly lower $(p<.01)$ rather than higher during pre-drug testing when compared with baseline scores, and pre-drug administration scores for PANSS anxiety and depression also tended to be marginally lower than baseline scores $(p<.10)$. For the two neurocognitive tests for which we had the strongest effects of smoking or nicotine nasal spray, the pre-drug experimental day scores on spatial rotation accuracy were significantly improved compared with baseline testing, whereas the two choice reaction time accuracy showed no significant difference between baseline and pre-drug testing. Several other tests from the ANAM battery, match to sample and Sternberg memory, showed either significant effects or trends for pre-drug scores on the experimental day to be better (higher) than baseline testing scores. There were no significant differences between scores on the pre-drug testing of the different experimental days and none of the ANOVAs showed a main effect or "order" effect, or an interaction effect between "testing occasion" and "order of drug administration". There were no significant differences between baseline and experimental day pre-drug means for total tardive dyskinesia scores on the Smith-TRIMS Tardive Dyskinesia scale. 


\section{DISCUSSION}

\section{Negative Symptoms}

The fact that negative symptoms and not other positive symptoms of schizophrenia or symptoms of anxiety, tension, or depression were affected by smoking cigarettes suggests that these symptoms may be more differentially affected in patients with schizophrenia who smoke. The differential effects of the high dose nicotine cigarette producing a greater effect on decreasing some measures of negative symptoms than the denicotinized cigarette, suggested that nicotine content of the high dose cigarette may be involved in this effect. The effects of the ultra low dose cigarette on reducing negative symptoms may be due to a pharmacological effect of the small amount of nicotine increase produced by this denicotinized cigarette. Although the extent of the nicotine plasma level increase produced by the denicotinized cigarette was much smaller than that produced by the high dose cigarette, this small increase presumably was sufficient to produce a pulse change equivalent to the high dose cigarette. Peak nicotine levels occur about $10 \mathrm{~min}$ after smoking. However, our blood samples were drawn about 35-40 min after smoking the second set of two cigarettes, because we did not want the stress associated with blood drawing to interfere with the symptom-based psychological measures we were obtaining earlier in the experiment. It is quite possible that the nicotine increase after the denicotinized cigarette would be considerably higher if measured 10$15 \mathrm{~min}$ after smoking. If we had used a placebo without any nicotine content, it is possible that the difference between high and placebo cigarettes would have been stronger. However, we were concerned that the subjects would detect a gross difference in the experience of smoking the high nicotine and a completely non-nicotine cigarette which cannot be made from tobacco leaves. None of our subjects spontaneously reported a different experience with the high vs. denicotinized cigarette we utilized in the current experimental design, although we did not systematically question them on this point. An earlier preliminary study, on an independent sample, by our group (Smith et al. 2001a) showed an effect of smoking both high or denicotinized cigarettes on reducing negative symptoms in schizophrenic patients, but no differential drug-cigarette effects, although there was a marginally greater decrease in negative symptoms after the high nicotine cigarette. The larger sample of the current study may have allowed us to detect the statistically significant difference between the high and denicotinized cigarette that we present in this report.

Our finding that negative symptom scores, but not scores of positive symptoms, depression, or anxiety, were uniformly raised in the pre-drug testing session on the experimental days, after 10-12 h of smoking ab- stinence, suggests that even short-term deprivation from smoking may specifically raise negative symptoms. The extent of decrease in SANS modified total and SANS affective flattening scores produced by the high nicotine cigarettes comparing pre-drug to postdrug evaluation was about a $20-35 \%$ decrease; this is in the same range of the degree of change as the percent increase (15-20\%) in these scores comparing baseline and pre-drug experimental day evaluation. This suggests that smoking cigarettes may return negative symptoms to baseline levels. However, if the rise in negative symptoms with short smoking abstinence were due to general withdrawal effects from nicotine or smoking, we might have expected to see increases in anxiety and depression scores also. On the contrary, there was a non-significant trend for anxiety and depression to be lower on the pre-drug testing on the experimental day than on baseline evaluation. Furthermore there were no drug effects on PANSS measures of anxiety, tension or depression. This suggests that the effects of smoking withdrawal may be specific for negative symptoms. However, the PANSS is not a scale designed to quantify drug withdrawal effects, and a more sensitive scale or procedure may have shown typical nicotine withdrawal effects. Since we did not include a specific nicotine withdrawal scale, we cannot definitively address this question.

There are other potential explanations of the reduced negative symptoms seen after the ultra low dose cigarette, which might also be relevant to the stronger effects we found in the high nicotine cigarette session. The behaviorally conditioned stimulus cues from the act of smoking itself, could generate effects similar to cigarettes with high nicotine content. O'Brien et al. (1998) have proposed that drug conditioned cues may be involved in some of the physiological and addictive properties of drugs of abuse. Westman et al. (1996) recently reported that, in volunteer normal chronic smokers, denicotinized cigarettes had many of the same subjective effects as the standard cigarettes smoked in their experiment. Furthermore, there is recent evidence that in some experimental situations, placebos themselves may increase dopamine levels, as was recently found in a sudy in patients with Parkinson's disease (de la Fuente-Fernandez et al. 2001). If this was also true for our patients in this experimental smoking day paradigm, then the decrease in negative symptoms might possibly also be mediated by physiological changes associated with the cue-enhanced placebo cigarette, which may potentially increase functional activity of dopaminergic transmission. Other components of cigarettes, found much more equally in the two cigarettes, and not the nicotine content of the cigarettes themselves, might potentially affect these responses. For example, several groups (Berlin et al. 1995; Fowler et al. 1996; Simpson et al. 1999) have reported decreases in platelet or brain 
MAO activity produced by cigarettes, which could theoretically increase brain dopamine activity. Nicotine itself does not inhibit MAO activity. However, the time course to reach a physiologically relevant degree of MAO inhibition in vivo may take days or weeks of cigarette smoking, and this is too long to account for the immediate effects on negative symptoms that we report.

The fact that the active nicotine spray did not produce a drug effect on negative symptoms, may be due to several factors. In the full experiment, both the sideeffects of nicotine nasal spray and the low nicotine plasma levels may have worked against an effect on negative symptoms. However, in the additional high dose small sample study, where we had higher nicotine plasma levels and most subjects had developed some tolerance to the side-effect of nasal spray, there was also no significant effect on negative symptoms. Although it is possible that this additional study was under-powered to detect significant effects on negative symptoms, the high dose spray did produce an effect on a cognitive measure, spatial processing. Overall, these results suggest that the act of smoking itself may be important for the psychological effect on negative symptoms, and that an increase in nicotine levels by itself may be not be sufficient to produce this effect.

\section{Cognitive Effects}

The stronger differential drug effects in the nasal spray as compared with the cigarette smoking sessions, suggest that nicotine itself may mediate some of the effects on improvement in spatial processing or memory and verbal recall. These positive effects on selected cognitive tests were seen in spite of the side effects produced by nasal spray in the full experiment; many of the subjects experienced minor nasal and throat irritation from the spray administration. The overall significant effect of pre- vs. post-cigarette administration scores for two of the cognitive functions (spatial rotation task, and two-choice reaction time) in the smoking sessions, but the lack of significant differential drug effect, may be due to the fact that the smaller increase in nicotine levels produced by the denicotinized cigarette may have attenuated drug vs. presumed placebo differences. Our positive results must be viewed as tentative and in need of further replication; because of the large number of tests performed and analyzed, it is possible that our positive results are due to chance since none of the differences were significant at Bonferroni corrected significance levels. The Bonferroni criterion, however, is a very conservative statistical procedure, which may not be fully appropriate for evaluation of multiple tests on closely related measures.

Our finding that performance on the spatial rotation task and two-choice reaction time, did not deteriorate with smoking abstinence as compared with baseline testing scores, suggests that the effects of nicotine we report are not due to withdrawal effects producing abnormally low performance scores. The significant increase in performance scores on some measures in the pre-drug testing compared with baseline, is most likely explained by a familiarity effect with the test procedure after an initial exposure. However, our results do not indicate a continued "practice effect" since the pre-drug baseline scores on the multiple experimental test days did not significantly vary.

Other research studies in normal smokers, and in patients with various disorders, have indicated that cigarette smoking and/or nicotine may improve memory, attention, and spatial perception (Levin 1992; Levin et al. 1996; Rezvani and Levin 2001). George and associates have presented preliminary data at meetings suggesting that smoking improves spatial working memory performance in schizophrenic patients (George et al. 2001a). Levin et al. (1996) presented data showing that, in schizophrenic patients treated with haloperidol, higher doses of nicotine patch improved reaction time in the spatial rotation task we used, but not the improvement in the accuracy of response on this task that we report. The nicotine patch also improved performance on a visual match to sample task. The main effect in the Levin study was reversal of haloperidolinduced deficits. The differences from our results may be due to the different forms of nicotine administration, and/or to the fact that most of our patients were on atypical antipsychotic drugs. Preliminary results from some studies suggest that nicotine administration may have different effects in patients on conventional vs. atypical drugs; for example, George et al. (2001b) reported that there was a considerably higher rate of short term smoking abstinence with nicotine patch in patients currently treated with atypical neuroleptics compared with conventional neuroleptics. Several studies have shown that smoking or nicotine administration improves short term and long term verbal memory or recall, especially in deprived smokers or patients with Alzheimers disease, but others have found no effects (Heishman et al. 1994; Levin 1992; Newhouse et al. 2001; Rezvani and Levin 2001). Patients with schizophrenia have been found to have particularly strong deficits in tests of verbal memory compared with normals (Saykin et al. 1991, 1994). Our suggestive effects of nicotine nasal spray on some measures of verbal memory function need further investigation to determine whether nicotinic agonists may benefit memory function in this group of patients who have been documented to have severe cognitive deficits in this domain. A comparison of cognitive function in these domains pre- and post-drug administration on the same day would be more informative. The cognitive tests utilized in the current study did not specifically address the classic measures of attention or vigilance which have 
been shown to be most consistently improved by smoking and other forms of nicotine administration in humans, and our experiment cannot specifically address this issue in schizophrenic patients. It is possible, however, that improved performance on the two-choice reaction time may represent an increase in attention or vigilance.

Desensitization and Tolerance to Nicotine's Effects. The lack of effects on some neurocognitive measures, and the less robust effects of smoking and nicotine nasal spray administration that we found on some others, may be due to rapid tolerance to some of nicotine's effects which may be related to rapid desensitization of nicotinic receptors. Previous research has suggested that the most rapid desensitization rate may be found in the $\alpha 7$ nicotinic receptors which are prevalent in the hippocampus (Domino 1998; Stevens et al. 1998), and have been hypothesized to be important in nicotine's effects on psychophysiological and cognitive function in schizophrenic patients. For example, Adler and associates have reported the ameliorating effects of smoking on normalization of the P50 auditory evoked response in schizophrenics shows rapid tolerance with continued smoking (Adler et al. 1993). In our experimental design, subjects had three separate nicotine drug administration over a $1.5-2 \mathrm{~h}$ period. We studied cognitive effects of smoking immediately after the second and third drug administration, whereas we examined the effects on negative symptoms after the first drug administration. It is possible that, there might have been stronger or more consistent effects on some of our cognitive measures if these functions had been studied after the first nicotine exposure. Alternatively, use of a nicotine agonist, such as GTS-1 or DMXB-A, which does not produce rapid tolerance in animal models (Stevens et al. 1998), might show stronger effects of nicotine in schizophrenic patients.

In contrast to nicotine, another class of drugs, atypical antipsychotics, have been shown to consistently improve cognitive function in schizophrenic patients during treatment with these medications (Meltzer and McGurk 1999; Keefe et al. 1999), although the effect size varies considerably. Moreover, these effects of atypical antipsychotics may increase over time rather than show tolerance. In a previous study with olanzapine that we performed in a sample of chronic medication refractory schizophrenic patients (similar to the subjects in the current study), we utilized some of the same measures, Randt Memory Scale and ANAM cognitive battery, that we utilized in the current study of smoking. In the earlier study olanzapine produced greater and more significant effects on improving cognition on multiple measures from the Randt and ANAM after five months of treatment than after two months (Smith et al. 2001b). Purdon et al. (2000) also reported somewhat greater effects of olanzapine on cognitive function with increasing length of drug treatment.

However, some physiological effects of nicotine do not appear to show rapid tolerance. Damsma et al. (1989) found no tolerance to the effects of nicotine on dopamine release in the nucleus accumbens. If increased dopaminergic tone mediates the effects of nicotine on decreasing negative symptoms, then this effect should not show rapid tolerance in schizophrenic patients who smoke for several hours. Repeated assessments of negative symptoms during chronic smoking would be needed to empirically answer this question.

Pulse and Nicotine Levels. Our results showing that the denicotinized cigarettes produced small increases in nicotine levels, and produced a fairly similar increase in pulse as the high nicotine cigarette, suggests that the denicotinized cigarette is pharmacologically active, and is not a perfect placebo. Our results further suggest that it may be useful to use multiple partial or imperfect placebos in cigarette research in this patient population. Our results showing that the placebo nasal spray did not increase nicotine levels or pulse suggest that this was an effective placebo for pharmacological effects. However, the side-effects produced by nasal spray administration, and the absence of appropriate smoking cues associated with nasal spray, may make it more difficult to replicate some of the subjective psychological effects of smoking with this form of nicotine administration.

Tardive Dyskinesia. The failure of smoking cigarettes or administration of nicotine nasal spray to produce increases in tardive dyskinesia contrasts with the results of Dalack and others (Dalack et al. 1999; Wirshing et al. 1989) who reported that nicotine patch or cigarette smoking produced increased in TD scores in schizophrenic patients. However most of our patients were being treated with atypical antipsychotic medications which have a very low propensity to produce tardive dyskinesia, whereas many of the patients in the earlier studies were on conventional antipsychotic medications. The TD scores in our subjects in this study were much lower than TD scores obtained, using the same scale, in a previous study of patients treated with conventional antipsychotic medication in the 1970s (Bell and Smith 1978); in that study $36 \%$ of patients had scores qualified for total TD scores $>5$ and $32 \%$ of patients had facial TD scores $>2$, whereas none of the patients in this study had TD scores in that range. Atypical antipsychotics may not produce the post-synaptic receptor dopaminergic supersensitivity which some models have postulated as underlying some of the pathophysiology of tardive dyskinesia. The increased release of dopamine produced by nicotine may therefore not have acted on a substrate of supersensitive 
dopamine receptors to result in the behavioral expression of increases in tardive dyskinesia symptoms.

In summary, our studies show an effect of acute administration of cigarettes on reducing negative symptoms in patients with schizophrenia, with a stronger effect for a cigarette with a higher nicotine content. Administration of nicotine by nasal spray improved performance on a spatial rotation task in schizophrenics, and there was suggestive evidence that smoking high nicotine cigarettes also improved this function. Active nicotine nasal spray also tended to improve some measures of short term verbal memory.

It is possible these effects of smoking or nicotine on ameliorating negative symptoms and cognitive deficits may help explain some of the reasons why patients with schizophrenia show such a high rate of cigarette dependence. If these ameliorative effects showed short term tolerance, it would provide a rationale as to why repeated intermittent smoking may be needed to maintain these beneficial effects. Whether tolerance develops to these effects needs to be determined in future studies that compare the behavioral effects of acute vs. repeated or chronic administration of cigarettes or other forms of nicotine administration. Continued study in this area may contribute to the understanding of the neurobiology underlying of both schizophrenia and cigarette addiction, and has the potential of suggesting avenues for new treatments of some of the deficits of schizophrenia and nicotine dependence.

\section{ACKNOWLEDGMENTS}

Supported by a NARSAD Independent Investigator Award to Dr. Smith

Active and placebo nicotine nasal spray (Nicotrol) was supplied by Pharmacia-UpJohn (Mikael Franzon, Ph.D.; Carol Spillers); Akeela Ali, B.A. Farishta Samimy, B.A., and Sanjay Nigam, M.D., assisted in some of the experimental procedures; Rhoda Lonow, M.S., of the Analytical Psychopharmacology Laboratory of the Nathan Kline Institute for Psychiatric Research (Director, Tom Cooper, M.A.) performed the nicotine and cotinine assays.

\section{REFERENCES}

Adler LE, Hoffer LD, Wiser BA, Freedman R (1993): Normalization of auditory physiology by cigarette smoking in schizophrenic patients. Am J Psychiatry 150:18561861

Adler LE, Hoffer LJ, Griffith J, Waldo MC, Freedman R (1992): Normalization by nicotine of deficient auditory sensory gating in the relatives of schizophrenics. Biol Psychiatry 32:607-616

Andreasen N (1983): The Scale for Assessment of Negative Symptoms (SANS). Iowa City, University of Iowa

Bell RCH, Smith RC (1978): Tardive dyskinesia: character- ization and prevalence in a statewide system. J Clin Psychiatry 39:39-47

Berlin I, Said S, Spreux-Varoquaux O, Olivares R, Launay JM, Puesch AJ (1995): Monoamine oxidase a and b activities in heavy smokers. Biol Psychiatry 38:756-761

Dalack GW, Becks L, Hill E, Pomerleau O, Meador-Woodruff JH (1999): Nicotine withdrawal and psychiatric symptoms in cigarette smokers with schizophrenia. Neuropsychopharmacology 21:195-202

Dalack GW, Healy DJ, Meador-Woodruff JH (1998): Nicotine dependence in schizophrenia: clinical phenomena and laboratory findings. Am J Psychiatry 155:1490-1501

Dalack GW, Meador-Woodruff JH (1996): Smoking, smoking withdrawal and schizophrenia: case reports and a review of the literature. Schizophrenia Rsch 22:133-141

Damsma G, Day J, Fibiger HC (1989): Lack of tolerance to nicotine-induced dopamine release in the nucleus accumbens. Eur J Pharmacol 168:363-368

Davis RA (1986): The determination of nicotine and continine in plasma. J Chromatographic Science 24:134-141

de la Fuente-Fernandez R, Ruth TJ, Sossi V, Schulzer M, Calne DB, Stossi AJ (2001): Expectation and dopamine release: mechanism of the placebo effect in Parkinson's disease. Science 293:1164-1166

Domino EF (1998): Tobacco smoking and nicotine neuropsychopharmacology: some future research Directions. Neuropsychopharmacology 18:456-468

Fagerstrom K, Schneider N (1989): Measuring nicotine dependence: A review of the Fagerstrom tolerance questionnaire. J Behav Med 12:159-181

Fowler JS, Volkow ND, Wang G-J, Pappas N, Logan J, MacGregor R, Axeloff D, Shea C, Schyler D, Wolf AP, Warner D, Zebulkova I, Cliento R (1996): Inhibition of monoamine oxidase B in the brains of smokers. Nature 379:733-736

Freedman R, Coon H, Myles-Worsley M, Orr-Utreger A, Olincy A, Davis A, Polymeropoulos M, Holik J, Hopkins J, Hoff M, Rosenthal J, Waldo MC, Reimherr F, Wender P, Yaw J, Young DA, Breese CR, Adams C, Patterson D, Adler LE, Kruglyak L, Leonard S, Byerley W (1997): Linkage of a neurophysiological deficit in schizophrenia to a chromosome 15 locus. Proceedings National Academy Sciences 94:587-592

George T, Vessicchio J, Sahady D, Head C, Termine A, Bregartner T, Kosten T, Wexler B (2001a): Effects of smoking abstinence on cognitive function in schizophrenia (abst.). Biol Psychiatry 49:5S

George T, Ziedonis DM, Feingold A, Pepper WT, Satterburg CA, Winkel J, Rounsaville BJ, Kosten TR (2001b): Nicotine transdermal patch and atypical antipsychotic medications for smoking cessation in schizophrenia. Am J Psychiatry 157: 1835-1842

Glassman A (1993): Cigarette smoking: Implications for psychiatric illness. Am J Psychiatry 150:546-553

Goff DC, Henderson DC, Amico E (1992): Cigarette smoking and schizophrenia: Relationship to psychopathology and medication side effects. Am J Psychiatry 149:1189-1194

Greenhoff J, Aston-Jones G, Svensson T (1986): Nicotinic effects on the firing pattern of midbrain dopamine neurons. Acta Physiol Scand 128:351-358 
Hall RG, Duhamel M, Clanahan R, Miles G, Nason C, Rosen S, Schiller P, Tao-Yonenaga L, Hall SM (1995): Level of functioning, severity of illness, and smoking status among chronic psychiatric patients. J Nerv Men Dis 183:468-471

Hamera E, Schneider J, Deviney S (1995): Alcohol, cannabis, nicotine and caffeine use and symptom distress in schizophrenia. J Nerv Men Dis 183:559-565

Heishman SJ, Taylor RC, Henningfeld JE (1994): Nicotine and smoking: A review of effects on human performance. Exp Clin Psychopharmacol 2:345-395

Kay SR, Fizzbein A, Opler LA (1987): The positive and negative syndrome scale (PANSS) for schizophrenia. Schizophrenia Bull 13:261-276

Keefe R, Silva S, Perkins DO, Lieberman JA (1999): The effects of atypical antipsychotic drugs on neurocognitive impairment in schizophrenia: A review and metaanalysis. Schizophr Bull 25:201-222

Levin E (1992): Nicotinic systems and cognitive functions. Psychopharmacology (Berl) 108:417-431

Levin ED, Wilson W, Rose JE, McEvoy J (1996): Nicotinehaloperidol interactions and cognitive performance in schizophrenics. Neuropsychopharmacology 15: 429-436

Lezak M (1983): Neuropsychological Assessment. New York, Oxford University Press

McGehee DS, Role LW (1995): Physiological diversity of nicotinic acetylcholine receptors expressed by vertebrate neurons. Annu Rev Physiol 57:521-546

Meltzer H, McGurk S (1999): The effects of clozapine, risperidone and olanzapine on cognitive function in schizophrenia. Schizophr Bull 25:233-255

Newhouse PA, Poter A, Kelton M, Corwin J (2001): Nicotinic treatment of Alzheimer's disease. Biol Psychiatry 49:268-278

Nilsson A, Waller L, Rosengren A, Adlerberth A, Wilhelmsen L (1997): Cigarette smoking is a risk factor for dyskinesias independent of medication exposure. Biol Psychiatry 41:717-723

O'Brien CP, Childress AR, Ehrman R, Robbins SJ (1998): Conditioning factors in drug abuse: can they explain compulsion? J Psychopharmacol 12:15-22

Olincy A, Ross RG, Young DA, Roath M, Freedman R (1998): Improvement in smooth pursuit eye movements after cigarette smoking in schizophrenics. Neuropsychopharmacology 18:175-185

Perkins K, Grobe J, Fonte C, Breus M (1992): "Paradoxical" effects of smoking on subjective stress versus cardiovascular arousal in males and females. Pharm Biochem Behav 42:301-311

Perkins K, Sextiob J, Stiller R, Fonte C, DiMarco A, Goettler J, Scierka A (1994): Subjective and cardiovascular responses to nicotine combined with caffeine during rest and casual activity. Psychopharmacology (Berl) 113:438-444

Pomerleau C, Pomerleau O (1992): Euphoriant effects of nicotine in smokers. Psychopharmacology (Berl) 108:460-465

Purdon S, Jones BDW, Stip E, Labelle A, Addington D, Davis SR, Brier A, Tollefson GD (2000): Neuropsychological change in early phase schizophrenia during 12 months of treatment with olanzapine, risperidone or haloperidol. Arch Gen Psychiatry 57:249-258
Randt CT, Brown ER (1983): Administration Manual: Randt Memory Test. Bayport, New York: Life Science Associates.

Reeves D, Kane R, Winter K, Ransford K, Pancella R (1993): Automated Neuropsychological Assessment Metrics (ANAM):Test Administration Guide, Version 1.0. St. Louis, MO, Institute of Mental Health

Rezvani A, Levin E (2001): Cognitive effects of nicotine. Biol Psychiatry 49:258-267

Saykin A, Gur RC, Gur RE, Mozley D, Mozley L, Resnick S, Kester B, Stafiniak P (1991): Neuropsychological function in schizophrenia: selective impairment in memory and learning. Arch Gen Psychiatry 48:618-624

Saykin A, Schatasel D, Gur R, Kester B, Mozley L (1994): Neuropsychological deficits in neuroleptic naive patients with first-episode schizophrenia. Arch Gen Psychiatry 51:124-131

Schneider N (1992): Efficacy of nicotine nasal spray (NNS): a double-blind, placebo controlled trial in smoking cessation, Kabi Research Report. Helsingborg, Sweden.

Shrout PE, Fleiss JL (1979): intraclass correlation: Uses in assessing rater reliability. Psychol Bull 86:420-428

Simpson G, Angus JSW (1970): A rating scale for extrapyramidal side effects. Acta Psychiatria Scandinavia 212: 9-11

Simpson GM, Shih JC, Chen K, Flowers C, Kumazawa T, Spring B (1999): Schizophrenia, monoamine oxidase activity, and cigarette smoking. Neuropsychopharmacology 20:392-394

Smith R, Allen R, Gordon J, Wolff J (1983): A rating scale for tardive dyskinesia and parkinsonian symptoms. Psychopharm Bull 19:266-276

Smith RC, Infante M, Ali A, Nigam S (2001a): Effects of cigarette smoking on psychopathology scores in schizophrenic patients: An experimental study. Substance Abuse 22:175-185

Smith R, Infante M, Singh A, Khandat A (2001b): Olanzapine's effects on neurocognitive functioning in medication refractory schizophrenia. International Journal of Neuropsychopharmacology 4:239-250

Stevens K, Kem WR, Mahnor VM, Freedman R (1998): Selective alpha-7 nicotinic agonist normalize inhibition of auditory response in DBA mice. Psychopharmacology (Berl) 136:320-327

Sugaya K, Giacobini E, Chiappinelli VA (1990): Nicotinic acetylcholine receptor subtypes in human frontal cortex: changes in alzhiemer's disease. J Neurosci Res 27:349-359

Sutherland G, Stapleton JA, Russel MAH (1992): Randomized controlled trial of nasal nicotine spray in smoking cessation. Lancet 340:324-329

Westman EC, Behm FM, Rose JE (1996): Dissociating the nicotine and airway sensory effects of smoking. Pharmacol Biochem Behav 53:309-315

Wirshing W, Engle J, Levin E (1989): The acute effects of smoking on tardive dyskinesia. Paper presented at New Research Program and Abstracts, San Francisco, CA, p 89

Zeidonis DM, Kosten TR, Glazer WM, Frances RJ (1994): Nicotine dependence and schizophrenia. Hosp Community Psychiatry 45:204-206 


\section{APPENDIX}

Items in modified PANSS scale used in pre- and post-interview on smoking day:

Positive symptoms: P1-delusions, P2-conceptual disorganization, P3-hallucinatory behavior, P5-grandiosity, P6-suspiciousness / persecution, P7-hostility
Negative symptoms: N1-blunted affect, N2-poor rapport, N6-lack of spontaneity, N7-stereotyped thinking

General symptoms: G2-anxiety, G4-tension, G-6 depression, G8-uncooperativeness, G9-unusual thought content, G11-poor attention

At baseline evaluation the full PANSS scale, not the abbreviated version specified above, was used. 